UNIVERSIDADE DE BRASÍLIA - UNB

\title{
INFLAÇÃO E INDEXAÇÃO - O EFEITO INERCIAL DOS REAJUSTES TARIFÁRIOS ANUAIS DE ENERGIA ELÉTRICA
}

DISSERTAÇÃO DE MESTRADO

DAVID AMOR GARRIDO

Brasília - DF 2016 
DAVID AMOR GARRIDO

\section{INFLAÇÃO E INDEXAÇÃO - O EFEITO INERCIAL DOS REAJUSTES TARIFÁRIOS ANUAIS DE ENERGIA ELÉTRICA}

Dissertação apresentada à Universidade de Brasília - UnB, como parte das exigências do Programa de Mestrado Profissional em Economia e Gestão do Setor Público, para a obtenção do título de Mestre.

Profa. Dra. Andrea Felippe Cabello

Orientadora

BRASÍLIA-DF

2016 


\section{DAVID AMOR GARRIDO}

\section{INFLAÇÃO E INDEXAÇÃO - O EFEITO INERCIAL DOS REAJUSTES TARIFÁRIOS ANUAIS DE ENERGIA ELÉTRICA}

Dissertação apresentada à Universidade de Brasília - UnB, como parte das exigências do Programa de Mestrado Profissional em Economia e Gestão do Setor Público, para a obtenção do título de Mestre.

Aprovada em de de

Prof. Dr. Roberto de Góes Ellery Júnior - FACE / UnB

Prof. Dr. Marcelo Driemeyer Wilbert - FACE / UnB

Profa. Dra. Andrea Felippe Cabello

Orientadora

BRASÍLIA-DF

2016 
A Samuel e Maria Vitória, que eu possa ajudar a deixar o mundo um pouco melhor para vocês e a formar vocês pessoas melhores para o mundo. 


\section{AGRADECIMENTOS}

A Deus, que nos mostra não os caminhos que achamos que queremos, mas aqueles que precisamos seguir.

Ao Ipea e à UnB, pela oportunidade de participar deste Programa de Mestrado, e à ANEEL, pelo apoio e incentivo à participação.

A Alex Sandro Feil, Marcos Bragatto e André Ruelli, pelo estímulo a que me mantivesse estudando e me aperfeiçoando.

A meus colegas da SMA/ANEEL, pelo companheirismo e por me ajudar a refinar meu conhecimento.

À Profa. Dra. Andréa F. Cabello, pela paciência e por ampliar em suas aulas minha curiosidade pelos temas de economia.

Aos demais professores do curso, cujas aulas me fizeram enxergar com outros olhos diversos conteúdos.

Aos meus colegas do Mestrado Profissional em Economia e Gestão do Setor Público, que me acompanharam nessa jornada.

A meus pais, Alexandre e Inez, por estarem sempre comigo, mesmo distantes.

A minha família, em especial minha avó Maria e minha madrinha Anna, por torcer e rezar por mim, sempre.

A Thalita, por me incentivar, me compreender e me estimular sempre a ser melhor. 
"Ilumina com a tua luz, mas defendes-te da tentação de te iluminar a ti mesmo. A espiritualidade do espelho é horrível" (Papa Francisco) 


\section{SUMÁRIO}

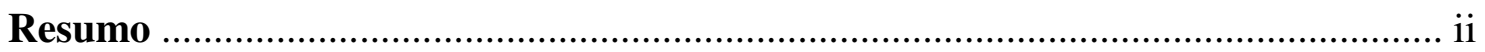

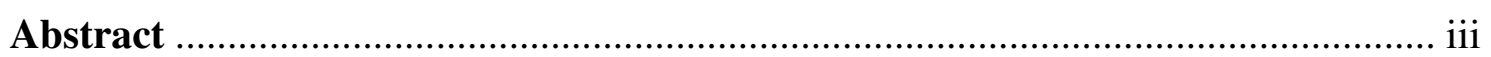

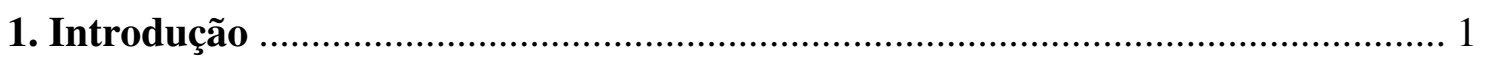

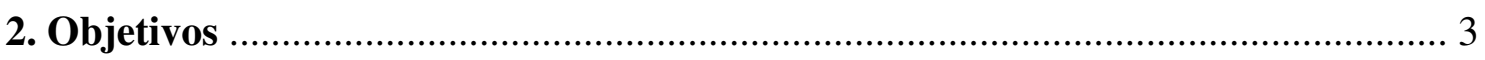

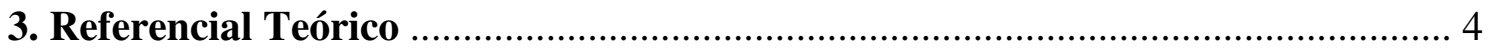

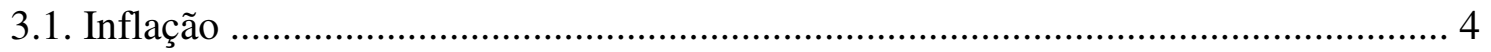

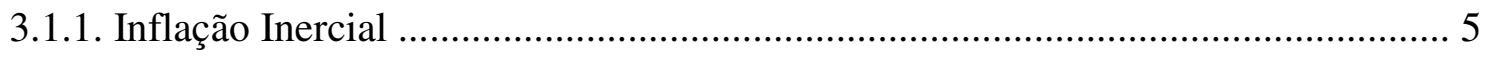

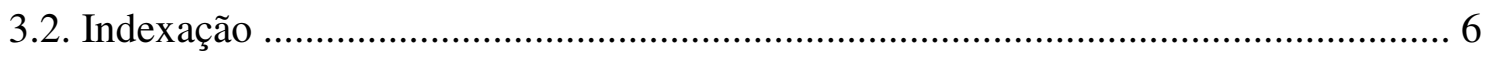

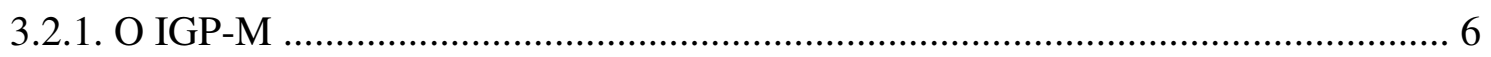

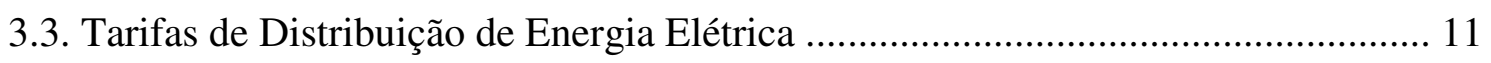

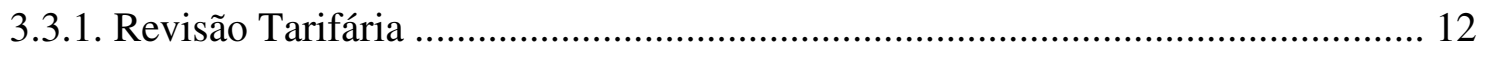

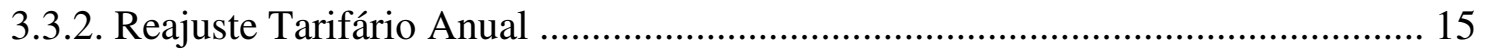

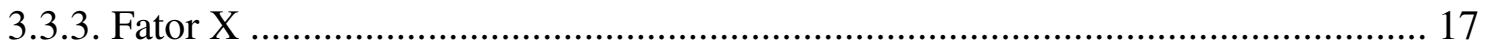

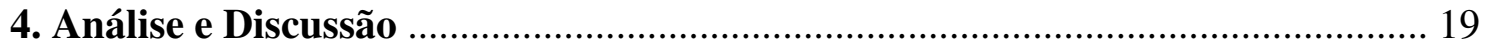

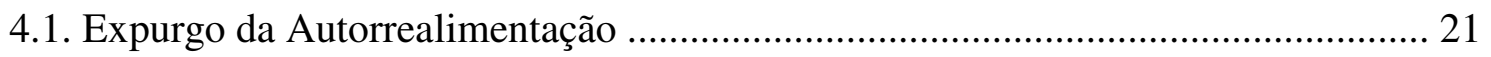

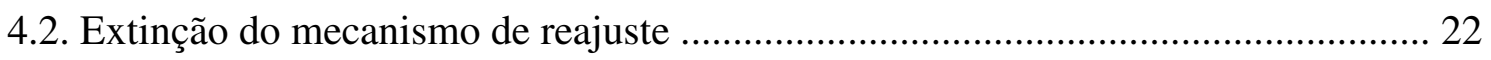

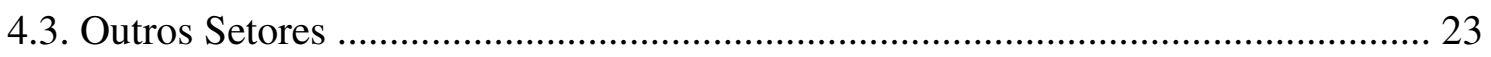

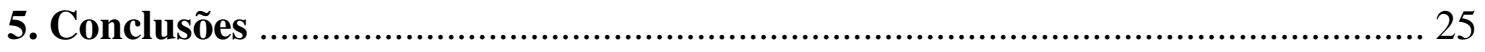

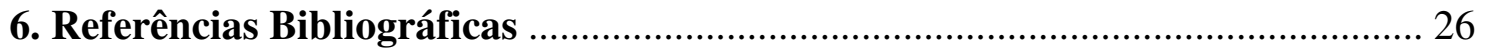




\section{RESUMO}

David Amor Garrido. Inflação e Indexação - O Efeito Inercial dos Reajustes Tarifários Anuais de Energia Elétrica

O alto grau de indexação da economia, mesmo após a estabilização alcançada com o Plano Real, acaba por se tornar um obstáculo ao combate da inflação, em especial quando se considera a indexação regulada de preços públicos, como as tarifas de energia elétrica. Tal fenômeno acaba por contribuir para perpetuar a inércia inflacionária, e se agrava pelo fato de os custos de energia serem um componente dos índices que são tomados como base para o reajuste das próprias tarifas de energia elétrica. O presente estudo busca, além de expor claramente tal situação e seu indesejado efeito sobre a inflação em termos numéricos, propor a adoção de mecanismos de correção que permitem, se não eliminar, ao menos mitigar os efeitos apontados.

Palavras-Chave: Inflação, Indexação, Reajuste, Tarifa. 


\begin{abstract}
David Amor Garrido. Inflation and Indexation - The Inertial Effect of Electricity Rate's Annual Adjustments

The high degree of indexation of brazilian economy, even after the stabilization achieved by "Plano Real", ends up becoming an obstacle to fighting inflation, especially when considering the indexation of public regulated prices such as electricity rates. This phenomenon ultimately contributes to perpetuate the inflationary inertia, and is aggravated by the fact that energy costs are a component of the indices used as a basis for the adjustment of those very electricity rates. This study aims, in addition to clearly demonstrate such situation and its undesired numerical effects on inflation, on the proposition of the adoption of correction mechanisms that allow, if not to eliminate, at least to mitigate the discussed effects.
\end{abstract}

Keywords: Inflation, Indexation, Inflationary Inertia. 


\section{INTRODUÇÃO}

Um dos temas mais presentes nas estratégias de política econômica e monetária, e uma preocupação constante por parte dos formuladores dessas políticas é o combate à inflação. Seu efeito, de reduzir o poder de compra da moeda, tem impactos mais severos geralmente sobre aqueles que já detém uma renda menor - pela impossibilidade de substituir determinados produtos por contrapartes mais baratas ou simplesmente abrir mão de produtos num orçamento já majoritariamente direcionado à subsistência.

Não obstante os problemas da aceleração da inflação, ao longo dos anos 50, 60, e mesmo durante a ditadura militar que se estendeu através dos anos 70, a combinação entre uma visão contrária a medidas estabilizadoras e a percepção de métodos inflacionários como um "caminho mais rápido" para o financiamento do desenvolvimento industrial desejado guiou as correntes econômicas dominantes, o que acabou por resultar na escalada inflacionária que se percebeu fortemente nos anos 80 e 90.

Um componente agravante desse cenário foram, sem dúvida, os mecanismos de indexação desenvolvidos em meados dos anos 60, que levavam a uma progressiva redução da preocupação com o problema da inflação em si. O professor Mario Henrique Simonsen identifica que, à época, os mecanismos de indexação colocavam a economia num estado de "quase neutralidade" em relação à inflação, reconhecendo, contudo, o risco de "um elevado coeficiente de realimentação inflacionária"(SIMONSEN, M. H. "Brasil 2002", 1975).

O advento do Plano Real, debelando o processo de hiperinflação, pode ser considerado um marco na história econômica recente do país, em especial quando comparado às diversas tentativas infrutíferas de estabilização anteriores. Esperar-se-ia que os mecanismos de indexação automática, parte da "cultura inflacionária" anterior, caíssem em desuso, ou ao menos tivessem seu emprego grandemente reduzido.

Não é o que se verifica, contudo, mais de vinte anos após a implantação do Plano Real. Indexações automáticas de contratos - de aluguel, por exemplo - persistem, e a situação se agrava quando tais cláusulas de reajuste são instituídas, não pelo contrato entre dois particulares, mas pela própria legislação, como é o caso de reajustes periódicos de tarifas de serviço público. 
O emprego de tais mecanismos tem por consequência indesejável a perpetuação de uma inercia inflacionária, visto que a inflação verificada de um ano alimenta o reajuste de preços (como alugueis ou tarifas de energia elétrica), reajustes que por sua vez são constatados pelo índice do ano posterior e repassados novamente aos preços.

Cabe então questionar se essa herança de períodos de inflação mais acelerada os diversos mecanismos automáticos de indexação - é adequada ao novo paradigma estabelecido pelo Plano Real e se não são exatamente tais mecanismos, que visariam compensar perdas inflacionárias, que perpetuam e amplificam o aquilo que buscariam, de alguma forma, combater. 


\section{OBJETIVOS}

O presente estudo tem por objetivo evidenciar, através de análise matemática, a distorção causada por mecanismos de indexação institucionalizados, que acabam por contribuir para a retroalimentação da inflação, com destaque para os mecanismos de reajuste tarifário anual no âmbito da distribuição de energia elétrica.

Além de apontar o mecanismo pelo qual o reajuste presente acaba por contribuir para o reajuste futuro, busca-se sugerir estratégias no sentido de minimizar tais impactos e seu potencial inflacionário. 


\section{REFERENCIAL TEÓRICO}

Para o desenvolvimento e compreensão do presente estudo, faz-se necessário adentrar nos conceitos de inflação e inflação inercial, bem como compreender o funcionamento e os efeitos da indexação.

É preciso também conhecer o arcabouço legal que rege a regulação econômica do Setor Elétrico Brasileiro, o funcionamento dos reajustes tarifários anuais e a forma como se calcula os índices tomados como base nesses reajustes.

\subsection{Inflação}

Inflação é associada, no jargão comum, com o aumento geral de preços de produtos e serviços em uma economia. Tal definição, embora reproduza o efeito mais perceptível da inflação, muitas vezes carece de certo rigor acadêmico.

Outra definição da inflação, centrada desta vez não no efeito final (o aumento dos preços em si), mas nos mecanismos que acabam por levar a tal aumento, caracterizam o processo inflacionário como sendo o processo de expansão monetária.

O próprio Banco Central do Brasil, em seu "Glossário Simplificado de Termos Financeiros", define inflação como "o aumento contínuo e generalizado do preço dos bens e serviços". Tem-se ainda a definição de inflação como "[...] aumento contínuo e generalizado no nível geral de preços" (VASCONCELLOS, 2001, p.331)

Em sintonia com essas definições, pode-se também afirmar que inflação representa a perda do poder de compra de uma determinada moeda, o que é uma definição especialmente útil, por que além de contemplar os efeitos sentidos pela população (um acréscimo dos preços frente à renda) e pelo conjunto da economia (maior oferta de moeda, diminuindo-lhe o valor individual), traz a informação de que o processo está se dando de forma localizada: aquela inflação verificada diz respeito àquela moeda estudada.

Uma das classificações mais habituais de inflação é a chamada inflação de demanda, resultante de um descompasso entre uma demanda crescente e uma oferta que 
não consegue acompanha-la: dessa forma, os preços tendem a se ajustar para compensar tal situação, elevando-se.

Observando-se o mesmo cenário do ponto de vista monetário, ter-se-ia uma expansão da oferta monetária, que não encontra contrapartida na oferta de produtos e serviços, o que acaba fazendo com que a moeda perca valor frente aos referidos produtos e serviços.

Sob essa ótica, fica mais claro de se entender o propósito de certas estratégias de combate à inflação, centradas na redução do crédito disponível, isto é, na oferta monetária disponível no mercado. Reduzindo-se o volume de moeda disponível no mercado, restabelece-se o equilíbrio entre oferta monetária e oferta de produtos e serviços, o que tem por consequência a retração dos preços.

\subsubsection{Inflação inercial}

Outro componente da inflação é a chamada inflação inercial. A inércia inflacionária pode resultar tanto de esquemas de indexação quanto de expectativas autorregressivas que reproduzem para o futuro a inflação passada. A inflação presente acaba por resultar da memória referente à inflação passada, perenizando-se.

O estudo da ligação entre indexação e inflação inercial aponta que a vinculação de preços de bens ou serviços a determinados índices de preços acabam por estabelecer uma relação linear homogênea entre os vários preços da economia.

Tal vinculação só será compatível com o equilíbrio dos mercados por pura coincidência, uma vez que as restrições estabelecidas - os reajustes de preços a cada produto ou serviço - podem ser incompatíveis com o equilíbrio de oferta e demanda daquele setor.

Ademais, as regras de indexação geralmente estabelecem pisos, mas não tetos para os preços de mercado, o que acaba por contribuir para que não ocorra uma condição de equilíbrio dos preços relativos. O ciclo acaba por perpetuar-se, com reajustes de preços e salários. 


\subsection{Indexação}

A indexação, de preços, salários e contratos, encontra-se firmemente enraizada na cultura econômica brasileira. "Nenhum país desenvolveu um sistema de indexação tão sofisticado quanto o adotado pelo Brasil até recentemente. [...]" (SIMONSEN, 1995, p.1).

A inserção de mecanismos de indexação se deu na década de 60, com o agravamento da desorganização da economia e a elevação dos patamares de inflação, e generalizou-se a partir daí. Procurava-se, com tais mecanismos, compensar as perdas com o processo inflacionário, e o amplo uso de cláusulas de correção monetária acabou, no período de 1968 a 1973, por ajudar a compatibilizar o crescimento acelerado do período com as taxas de inflação, ao custo da perpetuação de inflações passadas.

Foram indexadas as taxas de câmbio, os salários, os alugueis e prestações imobiliárias e as tarifas de serviços de utilidade pública, o que levou a indexação - formal e, muitas vezes, oficial - da economia a funcionar como um realimentador da inflação.

\subsubsection{O IGP-M}

O Índice Geral de Preços - Mercado (IGP-M) suscita a atenção do presente estudo pela amplitude com que é utilizado como referência de indexação em contratos: chamado informalmente de "inflação do aluguel", é o índice utilizado na maioria dos contratos imobiliários, bem como baliza as correções de alguns títulos emitidos pelo Tesouro Nacional e Depósitos Bancários com renda pós fixadas acima de um ano.

É também, razão principal do interesse presente, o índice de referência para a maioria dos reajustes tarifários anuais das distribuidoras de energia elétrica.

A Fundação Getulio Vargas (FGV), através do Instituto Brasileiro de Economia (IBRE), passou a calcular o IGP-M a partir de maio de 1989, e a base metodológica do índice é a estrutura do Índice Geral de Preços - Disponibilidade Interna (IGP-DI), que resulta da média ponderada de três outros índices de preços: o Índice de Preços ao Produtor Amplo (IPA-M), o Índice de Preços ao Consumidor (IPC-M) e o Índice Nacional de Custo da Construção (INCC-M), com pesos, respectivamente, de 60\%, 30\% e $10 \%$. 
Calcula-se o IGP-M para um período 't' qualquer através da seguinte expressão:

$$
I_{t}=0,6 \times X_{t}+0,3 \times Y_{t}+0,1 \times Z_{t}
$$

onde:

$I_{t}=$ IGP-M no período de referência ' $\mathrm{t}$ '.

$X_{t}=$ IPA-M no período de referência ' $\mathrm{t}$ '.

$Y_{t}=$ IPC-M no período de referência ' $\mathrm{t}$ '.

$Z_{t}=$ INCC-M no período de referência ' $\mathrm{t}$ '.

O IGP-M difere do IGP-DI nos seguintes aspectos:

a) Para efeito de coleta de preços, adota-se o período compreendido entre o dia 21 do mês anterior ao de referência e o dia 20 do mês de referência;

b) A cada mês de referência apura-se o índice três vezes, em intervalos cumulativos de dez dias, denominados decêndios;

c) os resultados das duas primeiras apurações prévias serão considerados valores parciais e o último será o resultado definitivo do mês.

Cada um desses índices, por sua vez, tem sua própria metodologia e composição.

O Índice de Preços ao Produtor Amplo (IPA-M) mede as variações médias dos preços recebidos pelos produtores domésticos na venda de seus produtos. A sua composição tem por base as pesquisas estruturais relativas aos setores agropecuário e industrial, além das Contas Nacionais, divulgadas pelo IBGE, sua periodicidade é mensal e ele é apurado com base em pesquisa sistemática de preços realizada nas principais regiões de produção do país. 
O índice pode ser obtido pela seguinte expressão:

$$
\operatorname{IPAM}_{t}=\sum_{i} w_{t}^{i} R_{t}^{i}
$$

Onde:

$I P A M_{t, t-1}=$ IPA-M do mês de referência $\mathrm{t}$

$w_{t}^{i}=$ Ponderação do produto i no mês de referência $\mathrm{t}$

$R_{t}^{i}=$ Relativo (variação de preço) do produto i no período $\mathrm{t}$

O Índice de Preços ao Consumidor - Mercado (IPC-M) mede variações intertemporais de preços de um conjunto fixo de bens e serviços componentes de despesas habituais de famílias com nível de renda situado entre 1 e 33 salários mínimos mensais, apurados em pesquisas realizadas em Belo Horizonte, Brasília, Porto Alegre, Recife, Rio de Janeiro, Salvador e São Paulo, subdividindo-se os bens e serviços pesquisados nos seguintes grupos: Alimentação; Habitação; Vestuário; Saúde e Cuidados Pessoais; Educação, Leitura e Recreação; Transportes; Despesas Diversas; e Comunicação.

O cálculo do índice é feito, inicialmente, no nível municipal, calculando-se primeiro o relativo de cada produto, e em seguida agregando-os por subitens, itens, subgrupos e grupos, chegando até o relativo municipal geral.

$$
\bar{R}_{t}^{x, k}=\frac{\sum_{s=1}^{\alpha x} \bar{R}_{t}^{s, k} W_{t}^{s, k}}{\sum_{s=1}^{\alpha x} W_{t}^{s, k}}
$$

Onde:

$\bar{R}_{t}^{x, k}=$ relativo ao grupamento x, do município ' $\mathrm{k}$ ', no período de referência ' $\mathrm{t}$ ' 
$W_{t}^{s, k}=$ ponderação do subitem 's', do município ' $\mathrm{k}$ ', no período de referência 't'.

$\bar{R}_{t}^{s, k}=$ relativo do subitem 's', do município ' $\mathrm{k}$ ', no período de referência ' $\mathrm{t}$ '.

$\alpha x=$ número de subitens pertencente ao grupamento $\mathrm{x}$.

Cabe ressaltar que cada produto, subitem ou item tem seu peso dentro do cálculo explicado. Observa-se abaixo uma parte da tabela contendo os pesos de cada produto na ponderação, onde se pode observar, por exemplo, o peso da tarifa de eletricidade residencial como um dos componentes do cálculo.

\begin{tabular}{|lr|}
\hline \multicolumn{2}{|c|}{ Pesos de alguns produtos e serviços na composição do IPC-M } \\
\hline Componente & Peso (consolidado Brasil) \\
\hline Aluguel residencial & 4,2540 \\
Condomínio residencial & 2,4452 \\
Tarifa de eletricidade residencial & 3,2818 \\
Gás de bujão & 0,7953 \\
Tarifa de gás encanado & 0,2084 \\
Tarifa de água e esgoto residencial & 1,6377 \\
Tarifa de telefone residencial & 1,7330 \\
\hline
\end{tabular}

Tabela 1. Pesos de alguns produtos e serviços na composição do IPC-M (Fonte: FGV. Metodologia IGP-M de Junho de 2015. Rio de Janeiro: 2015)

Em seguida, atribui-se a cada um dos municípios um peso fixo, equivalente à renda da população residente em cada um desses municípios em relação ao rendimento total do conjunto dos municípios.

\begin{tabular}{|cc|}
\hline MUNICÍPIOS & PARTICIPAÇÃ O (\%) \\
\hline Belo Horizonte & 8,47 \\
\hline Brasília & 8,21 \\
\hline Porto Alegre & 17,61 \\
\hline Recife & 7,24 \\
\hline Rio de Janeiro & 19,90 \\
\hline Salvador & 10,68 \\
\hline São Paulo & 27,89 \\
\hline TOTAL & $\mathbf{1 0 0 , 0 0}$ \\
\hline
\end{tabular}

Tabela 2. Pesos dos municípios na composição do IPC-M (Fonte: FGV. Metodologia IGP-M de Junho de 2015. Rio de Janeiro: 2015)

O Índice Nacional de Custo da Construção - Mercado (INCC-M) é um indicador econômico que mede a evolução de custos de construções habitacionais, abrangendo sete 
capitais - Belo Horizonte, Brasília, Porto Alegre, Recife, Salvador, Rio de Janeiro e São Paulo. O índice nacional resulta da média aritmética ponderada dos sete municípios.

O INCC-M é calculado através da conjugação de um sistema de pesos a um sistema de preços referentes a uma amostra de insumos (mercadorias, equipamentos, serviços e mão-de-obra) com representatividade na indústria da construção civil.

$$
\begin{gathered}
I_{t}=\sum_{M=1}^{n} Q^{M} I_{j, j-1}^{M} \\
I_{j, j-1}^{m}=\frac{\sum W_{t}^{i, M} \bar{R}_{t}^{i, M}}{\sum W_{t}^{i, M}}
\end{gathered}
$$

Onde:

$I_{t}=$ INCC no mês de referência ' $\mathrm{t}$ ';

$Q^{M}=$ peso do município ' $M$ ';

$I_{j, j-1}^{M}=$ índice do município ' $\mathrm{M}$ ', no mês de referência 'j' em relação ao mês imediatamente anterior ' $\mathrm{j}-1$ ';

$W_{t}^{i, M}=$ peso do insumo 'i', no município ' $M$ ', no período de referência ' $t$ ';

$\bar{R}_{t}^{i, M}=$ relativo médio do insumo 'i', no município 'M', no período de referência ' $\mathrm{t}$ '.

Também o INCC-M tem seus componentes ponderados segundo um sistema de pesos, que refletem a importância relativa dos itens no índice regional. Em sua definição, consideram-se a distribuição regional da construção residencial urbana, estimada a cada ano, e o detalhamento de itens de custo, também em nível regional, e suas respectivas participações nos custos atualizados para cada tipo de obra.

Por fim, os municípios estudados têm, cada, seu peso dentro do cálculo geral, que é sua importância relativa, em função da área total edificada segundo as licenças de "habite-se". 


\subsection{Tarifas de Distribuição de Energia Elétrica}

Integra a regulação econômica no Setor Elétrico Brasileiro a definição das tarifas de energia elétrica, que devem atender aos critérios de modicidade e manutenção do equilíbrio econômico-financeiro da concessão.

Modicidade, longe de significar simplesmente uma tarifa barata, se traduz numa tarifa que propicie uma remuneração justa - de acordo com os critérios legais - aos investimentos prudentes realizados, bem como a manutenção do serviço prestado, ao mesmo tempo em que não se torne excessivamente onerosa ao consumidor.

As tarifas cobradas dos consumidores de distribuição podem ser decompostas em dois agrupamentos principais: a parcela $\mathrm{A}$ - ou custos não gerenciáveis, aqueles componentes cuja gestão não se encontra sob a responsabilidade da distribuidora, como os custos de geração ou de transmissão, e são simplesmente repassados ao consumidor; e a parcela B - os custos gerenciáveis, em que há gestão possível da distribuidora, possibilitando-lhe obter ganhos de eficiência.

O presente trabalho tem seu foco na parcela $\mathrm{B}$ e em seus mecanismos de atualização tarifária. Os componentes da parcela A têm seus próprios mecanismos de atualização, estabelecidos em contrato.

Existem, atualmente, três mecanismos de atualização tarifária, estabelecidos nos contratos de concessão ou permissão das distribuidoras de energia elétrica. Tais mecanismos são a revisão tarifária periódica, a revisão tarifária extraordinária e o reajuste tarifário anual.

O funcionamento e a aplicação de tais mecanismos estão descritos nos Procedimentos de Regulação Tarifária - Proret, publicado pela Agência Nacional de Energia Elétrica - ANEEL (AGÊNCIA NACIONAL DE ENERGIA ELÉTRICA ANEEL. Procedimentos de Regulação Tarifária - Proret. Brasília, 24 mai. 2011). 


\subsubsection{Revisão Tarifária}

O mecanismo de revisão tarifária periódica é um pelo qual os custos de distribuição são revisitados, item a item, a fim de redefinir o nível eficiente dos custos operacionais e a remuneração dos investimentos.

Tal mecanismo, como sua denominação expressa, é executado com periodicidade fixada no contrato de concessão ou permissão da distribuidora, usualmente a cada quatro anos.

Já a revisão tarifária extraordinária acontece quando algum fato superveniente altera a situação do equilíbrio econômico-financeiro da concessão (ou permissão), podendo ser iniciado pelo órgão regulador ou a partir de solicitação da distribuidora avaliada e, eventualmente, aprovada pelo órgão regulador.

Uma revisão tarifária extraordinária pode ocorrer também frente a uma mudança do marco legal da distribuição, ensejando alguma alteração nas cláusulas econômicas da concessão.

Exemplos recentes de revisões tarifárias extraordinárias se deram em janeiro de 2013, em decorrência da Lei $n^{\circ} 12.783 / 2013$, que promoveu a renovação das concessões de transmissão e geração de energia que venciam até 2017, e em fevereiro de 2015 , quando as tarifas da maioria das distribuidoras foram reposicionadas em função da elevação dos custos de compra de energia.

Art. 12. O poder concedente poderá antecipar os efeitos da prorrogação em até 60 (sessenta) meses do advento do termo contratual ou do ato de outorga.

$\S 1$ lo A partir da decisão do poder concedente pela prorrogação, o concessionário deverá assinar o contrato de concessão ou o termo aditivo, que contemplará as condições previstas nesta Lei, no prazo de até 30 (trinta) dias contados da convocação.

$\S 2 o$ O descumprimento do prazo de que trata o $\S$ $1 o$ implicará a impossibilidade da prorrogação da concessão, a qualquer tempo. 
§ 3 o O concessionário de geração deverá promover redução nos montantes contratados dos CCEARs de energia existente vigentes, conforme regulamento.

Art. 13. Na antecipação dos efeitos da prorrogação de que trata o art. 12, o poder concedente definirá, conforme regulamento, a tarifa ou receita inicial para os concessionários de geração, transmissão e distribuição.

§ 1 o A Aneel realizará revisão extraordinária das tarifas de uso dos sistemas de transmissão para contemplar a receita a que se refere o caput.

$\S 20$ A Aneel procederá à revisão tarifária extraordinária das concessionárias de distribuição de energia elétrica, sem prejuízo do reajuste tarifário anual previsto nos contratos de concessão, para contemplar as tarifas a que se refere este artigo. (BRASIL. Lei $\mathrm{n}^{\circ}$ 12.783, de 11 de janeiro de 2013. Brasília, 14 jan. 2013. Grifo nosso)

O reposicionamento das tarifas na Revisão Tarifária é dividido em duas etapas: o cálculo da Receita Requerida - RR e, após a definição do Mercado de Referência, a abertura tarifária (por nível de tensão ou classe).

A Receita Requerida é composta pela soma da Parcela A e da Parcela B, conforme a fórmula a seguir:

$$
R R=V P A+V P B
$$

Onde:

RR: Receita Requerida; 
VPA: Valor da Parcela A, que incorpora os custos relacionados às atividades de transmissão e geração de energia elétrica, inclusive a geração própria, além dos encargos setoriais;

VPB: Valor da Parcela B, parcela que incorpora os custos típicos da atividade de distribuição e de gestão comercial dos clientes.

Por sua vez, as Parcelas A e B tem as seguintes composições:

$$
V P A=C E+C T+E S(2)
$$

Onde:

CE: Custo de aquisição de energia elétrica e geração própria;

CT: Custo com conexão e uso dos sistemas de transmissão e/ou distribuição;

ES: Encargos setoriais definidos em legislação específica.

$$
V P B=(C A O M+C A A) \cdot(1-P m-M I Q)-O \mathrm{R}
$$

Onde:

CAOM: Custo de Administração, Operação e Manutenção;

CAA: Custo Anual dos Ativos;

Pm: Fator de Ajuste de Mercado;

MIQ: Mecanismo de Incentivo á Melhoria da Qualidade;

OR: Outras Receitas.

(AGÊNCIA NACIONAL DE ENERGIA ELÉTRICA - ANEEL. Procedimentos

de Regulação Tarifária - Proret, Módulo 2, Submódulo 2.1. Brasília, 24 mai. 2011) 
O mercado de referência é composto pelos montantes de energia elétrica, de demanda de potência e de uso do sistema de distribuição, faturados no período de referência a outras concessionárias e permissionárias de distribuição, consumidores, autoprodutores e centrais geradoras que façam uso do mesmo ponto de conexão para importar ou injetar energia elétrica, bem como pelos montantes de demanda de potência contratada pelos demais geradores para uso do sistema de distribuição.

Por fim, a abertura tarifária é o processo através do qual, a partir da receita requerida, define-se a Estrutura Tarifária, o conjunto de tarifas, aplicadas ao faturamento do mercado de distribuição de energia elétrica, que refletem a diferenciação relativa dos custos regulatórios da distribuidora entre os subgrupos, classes e subclasses tarifárias, de acordo com as modalidades e postos tarifários.

O detalhamento de como cada uma dessas etapas transcorre pode ser encontrado nos Procedimentos de Regulação Tarifária - Proret, disponível na página eletrônica da ANEEL.

\subsubsection{Reajuste Tarifário Anual}

É o mecanismo de atualização do valor das tarifas pagas pelos consumidores, aplicado anualmente - exceto nos anos em que ocorre revisão tarifária periódica - de acordo com fórmula prevista no contrato de concessão da distribuidora.

Para fins de reajuste tarifário, a receita da distribuidora é dividida em duas parcelas: Parcela “A” e Parcela "B”.

A Parcela "A" envolve os custos relacionados às atividades de geração (compra de energia elétrica em função do mercado de referência) e transmissão de energia elétrica, além dos encargos setoriais previstos em legislação específica. Trata-se de custos cujos montantes e preços, em certa medida, escapam à vontade ou gestão da distribuidora.

A Parcela "B" compreende os custos diretamente gerenciáveis pela distribuidora. São custos próprios da atividade de distribuição que estão sujeitos ao controle ou influência das práticas gerenciais adotadas pela empresa, como os custos operacionais, a remuneração do capital e a quota de reintegração. 
Define-se a Receita Anual ( $\left.\mathrm{RA}_{0}\right)$, também denominada Receita de Referência, como a Receita Anual de Fornecimento, Suprimento, Consumo de Energia Elétrica e Uso dos Sistemas de Distribuição, calculada com base nas tarifas econômicas homologadas na Data de Referência Anterior (DRA) - a data de vigência do último processo tarifário homologado - e o mercado de referência, excluídos o PIS/PASEP, a COFINS, o ICMS e os componentes financeiros exógenos ao reajuste econômico.

Em seguida, define-se o valor da Parcela "A" $\left(\mathrm{VPA}_{0}\right)$, com base nos valores de cada um de seus componentes homologados no último reajuste ou revisão, e em seguida o valor atualizado da Parcela "A" $\left(\mathrm{VPA}_{1}\right)$, a partir de cada um de seus componentes, atualizados.

O valor da Parcela "B" $\left(\mathrm{VPB}_{0}\right)$ anterior é calculado a partir da expressão:

$$
V P B_{0}=R A_{0}-V P A_{0}
$$

Em seguida, tem-se que:

$$
V P B_{1}=V P B_{0} \times(I G P M-X)
$$

Onde:

IGPM: Índice Geral de Preços do Mercado, também designado IVI. É uma das versões do Índice Geral de Preços (IGP) calculado pela Fundação Getúlio Vargas (FGV);

X: Também designado Fator X. É o valor a ser subtraído do IGPM, ou IVI, com objetivo de compartilhar com os usuários e consumidores da distribuidora os ganhos de eficiência empresarial e da competitividade estimados para o período, contribuindo assim para a modicidade tarifária. $\mathrm{O}$ valor do Fator $\mathrm{X}$ a ser aplicado a cada Reajuste Tarifário Anual (RTA) é obtido conforme metodologia de cálculo estabelecida no Submódulo 2.5 do PRORET.

Em seguida, tem-se que: 


$$
R A_{1}=\left(V P A_{1}+V P B_{1}\right)
$$

Onde

$\mathrm{RA}_{1}$ : Receita Anual atualizada.

(AGÊNCIA NACIONAL DE ENERGIA ELÉTRICA - ANEEL. Procedimentos

de Regulação Tarifária - Proret, Módulo 3, Submódulo 3.1. Brasília, 24 mai. 2011)

Considerou-se aqui o IGP-M como referência em razão de ser esse o índice adotado na maioria dos contratos de concessão. Entretanto, caso algum contrato específico se baseasse no IPCA, bastaria substituí-lo na fórmula acima.

\subsubsection{Fator $\mathrm{X}$}

O Fator X tem como objetivo principal manter, nos reposicionamentos tarifários, o equilíbrio estabelecido na revisão tarifária entre receitas e despesas eficientes, e transferir para o consumidor parte dos ganhos potenciais de produtividade do segmento de distribuição de energia elétrica.

Como se pôde observar na seção anterior, o fator X se apresenta, no cálculo do reajuste tarifário, como um elemento que é subtraído do índice base a ser aplicado à parcela B.

$\mathrm{O}$ fator $\mathrm{X}$ é composto por três componentes: $\mathrm{P}_{\mathrm{d}}$, representando os ganhos de produtividade das distribuidoras de energia elétrica no período histórico analisado, ajustado pela variação observada do mercado e das unidades consumidoras; Q, um mecanismo de incentivo baseado na qualidade dos serviços técnicos e comerciais prestados por cada distribuidora aos seus consumidores; e T, que ajusta, ao longo de um período definido, os custos operacionais observados de cada concessionária ao custo operacional eficiente. 


$$
\text { Fator } \mathrm{X}=\mathrm{P}_{\mathrm{d}}+\mathrm{Q}+\mathrm{T}
$$

(AGÊNCIA NACIONAL DE ENERGIA ELÉTRICA - ANEEL. Procedimentos de Regulação Tarifária - Proret, Módulo 2, Submódulo 2.5. Brasília, 24 mai. 2011)

É importante ainda notar-se que, ainda que o fator $\mathrm{X}$ atenue o valor do índice aplicado para o reajuste, seja o IGP-M ou o IPC-A, sua presença não anula o efeito circular, dado que, numa hipotética ausência da autorrealimentação (se sua influência fosse expurgada), o novo índice aplicado ainda seria atenuado pelo fator X, resultando em reajustes menores. 


\section{ANÁLISE E DISCUSSÃO}

Verifica-se, da análise da composição do IGP-M, que um de seus componentes, o IPC-M, tem dentre seus componentes a tarifa de eletricidade residencial.

Considerando-se que a tarifa de eletricidade residencial é obtida a partir dos mecanismos de reajuste e revisão tarifária, e que, no caso do reajuste, aplica-se o IGP-M, pode-se observar uma referência cíclica quase que direta no presente caso, onde a magnitude do reajuste da energia elétrica em um período acaba por afetar a magnitude do próprio reajuste.

Observa-se da Tabela 1 que a tarifa de eletricidade residencial tem um peso de 3,2818\% no IPC-M. O IPC-M tem, ele próprio, um peso de $30 \%$ na composição do IGPM, o que permite calcular que a tarifa de eletricidade residencial representa $0,98454 \%$ do IGP-M, para o período analisado.

Conclui-se, portanto, que aproximadamente $1 \%$ (no período analisado) do reajuste incidente sobre a tarifa de eletricidade residencial - para as localidades estudadas - é repassado para o reajuste tarifário anual seguinte, através do IGP-M, sem que necessariamente nenhum custo efetivo da atividade de distribuição tenha sido alterado.

Esse percentual do reajuste anterior, embora aparentemente pequeno, tem impacto significativo, quando se considera a magnitude dos valores monetários no Setor Elétrico Brasileiro, pois é transferido para o reajuste seguinte - e, ciclicamente, para os posteriores.

Tome-se como exemplo o reajuste tarifário anual da distribuidora A, aprovado pela Resolução Homologatória $n^{\circ}$ 2.066, de 19 de abril de 2016. Percebe-se, à página 18 da Nota Técnica n 104/2016-SGT/ANEEL, de 18 de abril de 2016, que subsidiou a elaboração do ato normativo, que o IGP-M aplicado pelo período de referência foi de $11,56 \%$.

Ocorre que um dos componentes do IGP-M, o IPC-M, tem, dentre seus componentes, a tarifa residencial de energia elétrica nas sete cidades apuradas, Salvador, Brasília, Belo Horizonte, Recife, Rio de Janeiro, Porto Alegre e São Paulo. Consultandose, nas resoluções homologatórias referentes às distribuidoras responsáveis pelo fornecimento a cada uma das cidades, para os anos de 2015 e 2014, pode-se obter a 
variação da tarifa residencial de energia elétrica para o período imediatamente anterior base para o IGP-M adotado.

\begin{tabular}{|cccc|}
\hline MUNICÍPIO & $\begin{array}{c}\text { PESO DA } \\
\text { PARTICIPAÇÃO } \\
(\boldsymbol{\%})\end{array}$ & $\begin{array}{c}\text { VARIAÇÃO DA } \\
\text { RESIDENCIAL } \\
\text { DE ENERGIA } \\
(\boldsymbol{\%})\end{array}$ & $\begin{array}{c}\text { TARIFA DE ENERGIA } \\
\text { DO PERÍODO } \\
\text { ANTERIOR } \\
(\boldsymbol{\%})\end{array}$ \\
\hline Belo Horizonte & 8,47 & 3,2012 & 28,5858 \\
\hline Brasília & 8,21 & 3,2401 & 44,2642 \\
\hline Porto Alegre & 17,61 & 2,9539 & 26,3223 \\
\hline Recife & 7,24 & 3,1273 & 12,7389 \\
\hline Rio de Janeiro & 19,90 & 3,8452 & 40,3999 \\
\hline Salvador & 10,68 & 3,1985 & 15,4665 \\
\hline São Paulo & 27,89 & 3,1957 & 55,1055 \\
\hline
\end{tabular}

Tabela 3. Participação, peso e variação da tarifa residencial de energia por município

A partir dos dados da tabela 3, pode-se calcular o efeito dos reajustes anteriores das tarifas residenciais no IPC-M e, por consequência, no IGP-M, o que se reflete no reajuste do ano seguinte, através da seguinte expressão:

$$
\mathrm{EIPCM}=\sum\left(\text { Part }_{i} \times \text { Peso }_{i} \times \text { Var }_{i}\right)
$$

Onde:

$\mathrm{EIPCM}=$ Efeito no IPC-M

Part $_{i}=$ Participação, em \%, do município “i”"

$\mathrm{Peso}_{\mathrm{i}}=$ Peso da tarifa residencial de energia elétrica, em \%, na cesta de produtos do município "i"

$\operatorname{Var}_{i}=$ Variação da tarifa residencial de energia elétrica, em \%, no município “i”, no período 2014-2015

Com esses dados, calcula-se um valor de $1,2141 \%$ para o efeito dos reajustes tarifários anteriores sobre o IPC-M, o que significa que apenas os reajustes tarifários provocaram uma inflação percebida pelo IPC-M de 1,2141\%. 
Considerando-se que o IPC-M tem um peso de $30 \%$ no IGP-M, tem-se portanto que o efeito sobre o IGP-M foi de $0,3642 \%$, ou seja, apenas os reajustes tarifários provocaram uma inflação percebida pelo IGP-M de $0,3642 \%$, repassada para o reajuste. No caso analisado da distribuidora A, esse percentual representa um valor de $\mathrm{R} \$$ 7.470.079,30 de crescimento da Parcela B apenas por causa da autorrealimentação.

Cabe observar que a magnitude das variações das tarifas de energia elétrica, no período de 2014-2015, foi extremamente elevada, em decorrência dos efeitos da Revisão Tarifária Extraordinária homologada pela Resolução Homologatória nº 1.858, de 27 de fevereiro de 2015, que reposicionou as tarifas da maioria das distribuidoras, devido a uma elevação dos custos de compra de energia. Percebe-se, portanto, que a autorrealimentação acaba por internalizar no índice de inflação e, portanto, no reajuste subsequente, efeitos decorrentes de um evento pontual.

Observa-se ainda que a metodologia do IPC-A, outro índice de inflação, calculado pelo IBGE, inclui entre seus componentes o custo de energia elétrica residencial, o que leva a crer que, ainda que o IGP-M fosse substituído por outro índice de inflação, como o IPC-A, a circularidade percebida nos Reajustes Tarifários Anuais tenderia a se manter.

O que se busca, então, são formas de eliminar, ou ao menos atenuar, a autorrealimentação que foi percebida, e duas alternativas, com diferentes graus de complexidade e esforço regulatório, são vislumbradas.

\subsection{Expurgo da Autorrealimentação}

Quando do cálculo do reajuste tarifário, tem-se a metodologia empregada para o cálculo do IGP-M que está sendo utilizado como base para o reajuste. É possível, portanto, obter-se o peso atribuído, em cada cidade pesquisada, à tarifa de eletricidade residencial, bem como o peso que cada cidade tem no índice geral para o cálculo do IPC$\mathrm{M} \mathrm{e}$, consequentemente, do IGP-M.

Da mesma forma, tem-se os valores da variação de preço das tarifas de eletricidade residencial para cada uma das cidades consideradas para o período do reajuste, dado que tais valores foram calculados pela própria ANEEL. 
É possível, portanto, como realizado na seção anterior, calcular a inflação medida pelo IGP-M que resultou somente dos reajustes de energia elétrica, o que tornaria possível expurgar os componentes referentes à participação da tarifa de eletricidade residencial na composição do IGP-M, criando-se assim um "IGP-MSE", que poderia ser aplicado no lugar do IGP-M no cálculo da Parcela B reajustada.

Aplicando-se tal raciocínio ao que se verificou no caso da distribuidora A, tratado na Resolução Homologatória $\mathrm{n}^{\mathrm{o}} 2.066$, de 19 de abril de 2016, e na Nota Técnica $\mathrm{n}^{\text {o }}$ 104/2016-SGT/ANEEL, de 18 de abril de 2016, teríamos um efeito dos reajustes tarifários anteriores de 0,3642\%, que aplicado ao IGP-M do período de 11,56\%, nos dá um IGP-M $\mathrm{SE}_{\mathrm{SE}}$ de 11,1958\%, sendo esse o índice adotado na fórmula de reajuste.

$$
V P B_{1}=V P B_{0} \times\left(I G P M_{\mathrm{SE}}-X\right)
$$

Como citado anteriormente, tal substituição, mantidas todas as demais condições, resultaria num valor de Parcela B menor em $\mathrm{R} \$ 7.470 .079,30$.

\subsection{Extinção do mecanismo de reajuste}

Uma forma de se evitar os prejuízos com a indexação e a consequente autoretroalimentação do modelo indexado seria a extinção do mecanismo de Reajuste Tarifário Anual.

Para que tal alteração não acabasse prejudicando o equilíbrio econômicofinanceiro das concessões, contudo, seria necessário aumentar a frequência com que se realizam as Revisões Tarifárias Periódicas.

Essa alternativa, mais que uma proposta, contempla um debate sobre o assunto. Existem atualmente 63 concessionárias de distribuição de energia elétrica, além de 38 permissionárias de distribuição de energia elétrica.

O esforço necessário para realizar as Revisões Tarifárias Periódicas, no atual ciclo de quatro anos, já demanda todo o recurso humano que a ANEEL tem para tanto, uma vez que o processo de revisão é muito mais completo e complexo que os reajustes anuais. 
Dessa forma, ampliar a frequência com que as Revisões Tarifárias Periódicas ocorrem demandaria uma força de trabalho maior, ou técnicas e capacidade computacionais mais pesadas, ou, provavelmente, ambos.

Tudo isso representa um custo para o Estado, e cabe, nesse caso, à sociedade, na forma de seus representantes, debater se benefício de tarifas calculadas com maior precisão - possivelmente menores - compensaria o custo adicional necessário em termos de infraestrutura e força de trabalho.

É importante ainda ressaltar que, no momento atual, a forma como são realizados os reajustes e revisões fazem parte dos contratos de concessão e permissão estabelecidos com as distribuidoras, e que sua alteração poderia demandar a assinatura de termos aditivos pelas partes envolvidas.

\subsection{Outros Setores}

Ressalte-se também que o setor elétrico não é o único em que se verifica tal efeito: na mesma Tabela 1, pode-se observar que o aluguel residencial é componente do IPC-M, e, conforme já foi ressaltado, o IGP-M é o índice majoritariamente adotado para o reajuste anual de alugueis.

No caso do setor de alugueis, contudo, pode-se afirmar que, conquanto seja a praxe a aplicação de reajustes anuais baseados no IGP-M, por se tratar de contratos entre dois particulares, nada impede que cláusulas diferentes sejam negociadas, inclusive excluindo a existência de um reajuste indexado e abrindo a possibilidade de renegociações periódicas dos valores.

Mais grave que no setor de aluguel de imóveis é a situação do setor de medicamentos. Segundo Alves (2016, p.46), "salta aos olhos o fato de que o IPCA está presente diversas vezes na formulação do reajuste" e "as variáveis [...] taxas de câmbio e preços da energia elétrica, têm uma significativa participação no cálculo do IPCA, ao impactar diretamente os preços de vários produtos da cesta pesquisada para o cômputo do índice. Por fim, o próprio valor dos medicamentos ao consumidor final compõe essa mesma cesta de produtos". 
Conclui o autor que " [...] a presença do IPCA na formulação é uma importante fonte de endogeneidade e circularidade. Na melhor das hipóteses, cria-se um problema de inércia inflacionária [...]” (Alves, 2016, p. 46, grifos nossos) 


\section{CONCLUSÕES}

A componente inercial da inflação acaba por se tornar um empecilho às políticas de combate à inflação desenvolvidas pelo governo. Pouco afetada pela atuação do Banco Central na política monetária, essa componente inercial é, muitas vezes, perpetuada através de mecanismos de indexação automáticos, e até mesmo oficiais, estabelecidos na legislação.

Cabe, portanto, analisar, enquanto sociedade, o quanto a herança de períodos altamente inflacionários - na forma de mecanismos de indexação automática - não acabou por se tornar um empecilho para o combate à inflação.

No que tange às tarifas de distribuição de energia elétrica, percebe-se que acaba por surgir uma situação em que o próprio reajuste da tarifa repercute no reajuste seguinte de maneira quase direta.

Lidar com a questão requer a alteração na forma como se calcula o reajuste tarifário anual das distribuidoras de energia elétrica, ou até mesmo a extinção de tal mecanismo, substituindo-o por revisões tarifárias periódicas - um mecanismo que faz uma análise mais aprofundada dos custos da atividade - mais frequentes, o que não seria possível sem uma alteração no panorama contratual e no dimensionamento dos recursos disponíveis à Agência Nacional de Energia Elétrica. Para tanto, cabe à sociedade debater se o benefício obtido em termos de combate à componente inercial da inflação justificaria os maiores custos com a estrutura de regulação.

É possível, ainda avançar ainda mais na matéria - o que pode ser alvo de estudos posteriores - uma vez que, além da componente direta de autorrealimentação, é possível inferir que a maioria, se não todos os componentes dos índices de inflação utilizados no reajuste sofrem, de alguma maneira, influência dos custos com energia elétrica. Identificar esse efeito indireto, e reduzir sua influência, é um desafio extremamente complexo, mas que poderia contribuir para o combate à componente inercial da inflação. 


\section{REFERÊNCIAS BIBLIOGRÁFICAS}

AGÊNCIA NACIONAL DE ENERGIA ELÉTRICA. Procedimentos de

Regulação Tarifária - $\quad$ PRORET. Disponível em http://www.aneel.gov.br/procedimentos-de-regulacao-tarifaria-proret. Acesso em 21 de Julho de 2016.

AGÊNCIA NACIONAL DE ENERGIA ELÉTRICA. Resolução Homologatória no 2.066, de 19 de abril de 2016. Brasília, 2016.

AGÊNCIA NACIONAL DE ENERGIA ELÉTRICA. Nota Técnica nº 104/2016SGT/ANEEL. Brasília, 2016.

AGÊNCIA NACIONAL DE ENERGIA ELÉTRICA. Resolução Homologatória no 1.878, de 14 de abril de 2015. Brasília, 2015.

AGÊNCIA NACIONAL DE ENERGIA ELÉTRICA. Resolução Homologatória n' 1.714, de 15 de abril de 2014. Brasília, 2014.

AGÊNCIA NACIONAL DE ENERGIA ELÉTRICA. Resolução Homologatória no 1.920, de 30 de junho de 2015. Brasília, 2015.

AGÊNCIA NACIONAL DE ENERGIA ELÉTRICA. Resolução Homologatória n $^{\circ}$ 1.759, de 3 de julho de 2014. Brasília, 2014.

AGÊNCIA NACIONAL DE ENERGIA ELÉTRICA. Resolução Homologatória no 1.937, de 25 de agosto de 2015. Brasília, 2015.

AGÊNCIA NACIONAL DE ENERGIA ELÉTRICA. Resolução Homologatória no 1.779, de 19 de agosto de 2014. Brasília, 2014.

AGÊNCIA NACIONAL DE ENERGIA ELÉTRICA. Resolução Homologatória $\mathbf{n}^{0} \mathbf{1 . 8 8 5}$, de 22 de abril de 2015. Brasília, 2015.

AGÊNCIA NACIONAL DE ENERGIA ELÉTRICA. Resolução Homologatória $\mathrm{n}^{\circ}$ o 1.723 , de 28 de abril de 2014. Brasília, 2014.

AGÊNCIA NACIONAL DE ENERGIA ELÉTRICA. Resolução Homologatória $\mathbf{n}^{0}$ 1.872, de 7 de abril de 2015. Brasília, 2015.

AGÊNCIA NACIONAL DE ENERGIA ELÉTRICA. Resolução Homologatória n⿳1.700, de 7 de abril de 2014. Brasília, 2014. 
AGÊNCIA NACIONAL DE ENERGIA ELÉTRICA. Resolução Homologatória n' 1.982 de 5 de novembro de 2015. Brasília, 2015.

AGÊNCIA NACIONAL DE ENERGIA ELÉTRICA. Resolução Homologatória no 1.820, de 4 de novembro de 2014. Brasília, 2014.

AGÊNCIA NACIONAL DE ENERGIA ELÉTRICA. Resolução Homologatória no 1.971, de 20 de outubro de 2015. Brasília, 2015.

AGÊNCIA NACIONAL DE ENERGIA ELÉTRICA. Resolução Homologatória n 1.834, de 5 de dezembro de 2014. Brasília, 2014.

ALVES, Lucas Bispo de Oliveira. A Regulação de Preços de Medicamentos: Aspectos Gerais e Críticas à Metodologia Brasileira de Reajustes. 2016. Dissertação (Mestrado em Ciências Econômicas) - Faculdade de Administração, Contabilidade e Economia, Universidade de Brasília. Brasília, 2016.

BANCO CENTRAL DO BRASIL - BCB. Glossário Simplificado de Termos Financeiros.

Disponível

em

http://www.bcb.gov.br/pre/pef/port/glossario_cidadania_financeira.pdf. Acesso em 10 de Junho de 2016.

BRASIL. Lei no 12.783, de 11 de janeiro de 2013. Brasília, 14 jan. 2013

DUBOIS, Alexy et al.Gestão de custos e formação de preços: conceitos, modelos e instrumentos: abordagem do capital de giro e da margem de competitividade. 3. Ed. São Paulo: Atlas, 2009.

FUNDAÇÃO GETÚLIO VARGAS - FGV. Metodologia Índice Geral de Preços - Mercado (IGP-M) Junho de 2015. Rio de janeiro: 2015.

INSTITUTO BRASILEIRO DE GEOGRAFIA E ESTATÍSTICA - IBGE. Sistema Nacional de Índices de Preços ao Consumidor Métodos de cálculo 7a edição. Rio de janeiro: 2013.

SIMONSEN, Mario Henrique. 30 Anos de Indexação. 1. ed. Rio de Janeiro: Editora da Fundação Getúlio Vargas, 1995.

SIMONSEN, Mario Henrique. Inércia Inflacionária e Inflação Inercial. Rio de Janeiro: 1988. 
VASCONCELLOS, Marco Antonio Sandoval de. Economia: micro e macro. 2. ed. São Paulo: Atlas, 2001. 